\title{
A genetic algorithm approach for assessing soil liquefaction potential based on reliability method
}

\author{
M H Bagheripour ${ }^{1}$, I Shooshrasha ${ }^{2, *}$ and M Afzalirad $^{3}$ \\ ${ }^{1}$ Civil Engineering Department, Shahid Bahonar University of Kerman, P.O. Box 133, \\ 76156, Kerman, Iran. \\ ${ }^{2}$ Civil Engineering Faculty, Babol University of Technology, P.O. Box 47144, Babol, Iran. \\ ${ }^{3}$ Civil Engineering Department, Islamic Azad University, Qaemshahr branch, Iran. \\ *Corresponding author.e-mail: Shooshpasha@nit.ac.ir
}

\begin{abstract}
Deterministic approaches are unable to account for the variations in soil's strength properties, earthquake loads, as well as source of errors in evaluations of liquefaction potential in sandy soils which make them questionable against other reliability concepts. Furthermore, deterministic approaches are incapable of precisely relating the probability of liquefaction and the factor of safety (FS). Therefore, the use of probabilistic approaches and especially, reliability analysis is considered since a complementary solution is needed to reach better engineering decisions. In this study, Advanced First-Order Second-Moment (AFOSM) technique associated with genetic algorithm (GA) and its corresponding sophisticated optimization techniques have been used to calculate the reliability index and the probability of liquefaction. The use of GA provides a reliable mechanism suitable for computer programming and fast convergence. A new relation is developed here, by which the liquefaction potential can be directly calculated based on the estimated probability of liquefaction $\left(P_{L}\right)$, cyclic stress ratio (CSR) and normalized standard penetration test (SPT) blow counts while containing a mean error of less than $10 \%$ from the observational data. The validity of the proposed concept is examined through comparison of the results obtained by the new relation and those predicted by other investigators. A further advantage of the proposed relation is that it relates $\mathrm{P}_{L}$ and FS and hence it provides possibility of decision making based on the liquefaction risk and the use of deterministic approaches. This could be beneficial to geotechnical engineers who use the common methods of FS for evaluation of liquefaction. As an application, the city of Babolsar which is located on the southern coasts of Caspian Sea is investigated for liquefaction potential. The investigation is based primarily on in situ tests in which the results of SPT are analysed.
\end{abstract}

\section{Introduction}

Evaluation of soil liquefaction potential by empirical methods and semi-empirical methods have become popular among practising engineers. These methods use deterministic relations to develop bounds or boundary curves to imply the occurrence or triggering of liquefaction. A semi-empirical method originally developed by Seed and Idriss
$(1971,1982)$ was based on the evaluation of soil liquefaction resistance indexed by the results of the standard penetration test (SPT). Over the past decades, the method has been modified successively (Seed et al 1985; Youd et al 2001), and has become more attractive and a standard of practice for many engineers around the world. Idriss and Boulanger (2006, 2008) discussed and presented the most recent updates introduced to this method

Keywords. Liquefaction; reliability method; genetic algorithm; earthquake; probability of liquefaction; factor of safety. 
which include recommended relations for different parts of the method's analytical framework.

Alternative methods such as probabilistic approaches to evaluate the failure probability and liquefaction probability (in this study), have been developed to complement the liquefaction potential evaluation. In a probabilistic analysis, the liquefaction potential is usually expressed as a function of liquefaction probability using various approaches (Liao et al 1988; Youd and Noble 1997; Toprak et al 1999; Juang et al 2002). Christian and Swiger (1975) analysed the available SPT data from field observation of soil performance and presented the probability of liquefaction. Liao et al (1988) used logistic regression analysis to characterize the boundary curve statistically and to estimate the probability of liquefaction as a function of earthquake load and SPT resistance. Toprak et al's (1999) statistical procedure shows that the boundary curve corresponds to a specific percentage of probability of liquefaction. Halder and Tang (1979) used the SPT results and carried out a secondmoment statistical analysis to examine the limitstate and empirical procedure introduced by Seed and Idriss (1971). Advanced first-order secondmoment (AFOSM) technique has recently been used to calculate the reliability index and its distribution characteristics as well as the probability of failure (Juang et al 1999). Juang et al (2006) performed an extensive series of sensitivity analyses using first-order reliability method associated with mapping functions in order to characterize the uncertainties in performance function. Ellipsoid method (Low and Tang 1997) has been used by Juang et al (1999) to carry out the minimization analysis and calculation of reliability index.

In this study, a reliability-based method is used to calculate the probability of failure and to assess liquefaction potential. The minimization of reliability index over the failure domain corresponding to the limit state function may be performed using various numerical techniques. However, for the first time, the use of genetic algorithm (GA) and the associated optimization techniques are introduced in this paper for advanced probabilistic analysis of liquefaction. This specific concept has been adopted here mainly because (1) the method does not deal with the derivatives of the performance function as required in some of the optimization techniques. (2) It can be easily and effectively performed by computer; since the variables can be transformed into their corresponding binary values (codes). (3) The method is more flexible than others because only the information on quality of the results is required. (4) It can be easily incorporated into commercially available scientific/mathematical software systems (e.g., Matlab) for universal access and increase in computational speed. Further, a great advantage of the method presented here is that it relates the liquefaction probability to the factor of safety (FS). It is shown that the higher FS against liquefaction does not necessarily mean a safer state. The ultimate judgment should be made based on FS, the probability of liquefaction occurrence, and the reliability index. Comparison is also made between the results obtained by the current concept and those presented by other investigators. The method presented here is applied to a case study in which earthquake hazard in a region is investigated with regard to liquefaction phenomenon. Probabilities of liquefaction are calculated based on the reliability index and GA optimization technique for various locations in the area where results of field tests (SPT) are also available.

\section{Practical criteria and field characterization}

Detailed investigation of actual earthquake case histories has allowed determination of in situ properties such as SPT (or CPT) resistance for each case history. Seed and Idriss's (1971) simplified method is a common approach to estimate cyclic stress ratio $\left(\mathrm{CSR}\right.$ or $\mathrm{CSR}_{\mathrm{N}}$ ) as a function of peak

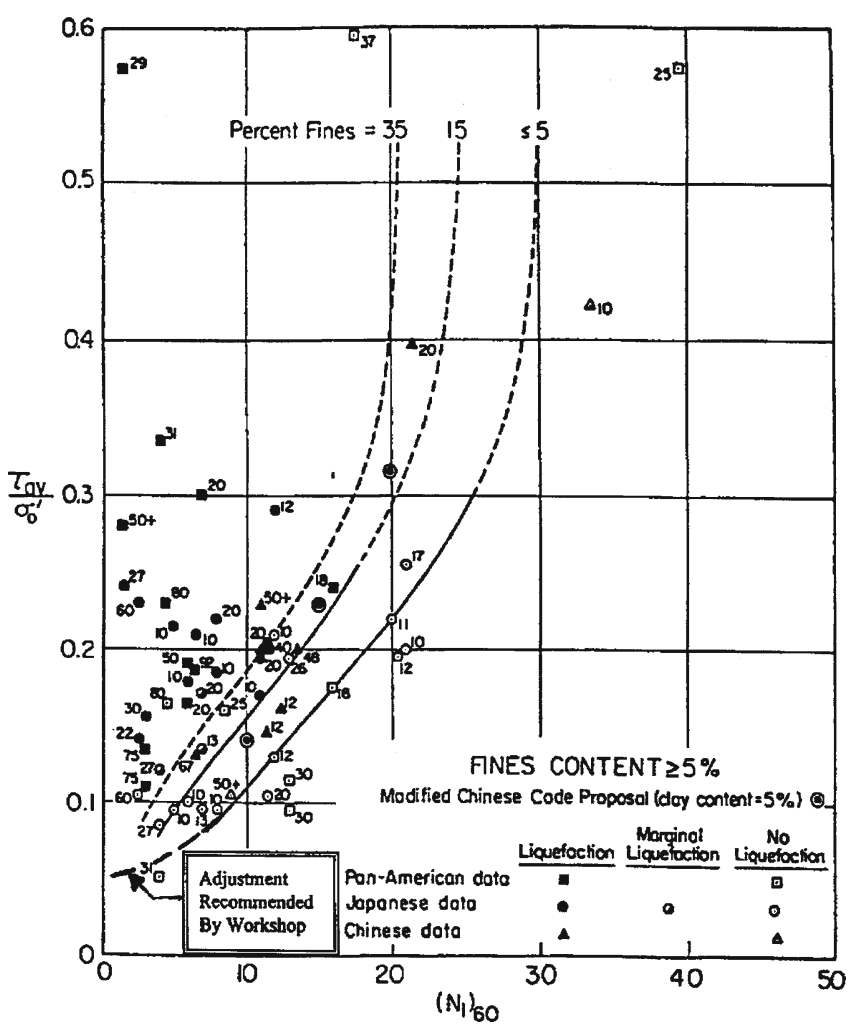

Figure 1. Experimental data and boundary curve proposed by Seed et al (1984) (modified by and cited in Seed et al 2003). 


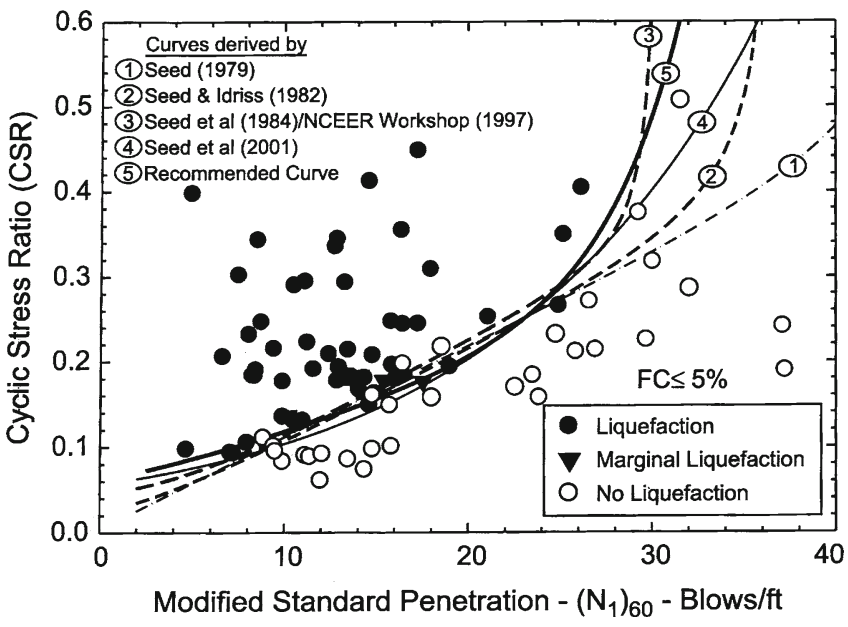

Figure 2. Curves relating CRR to $\left(N_{1}\right)_{60}$ published over the past 24 years for clean sands and the recommended curve for $M=7.5$ and $\sigma_{v 0}^{\prime}=1 \mathrm{~atm}$ (adapted from Idriss and Boulanger 2006).

ground surface acceleration amplitude. By plotting CSR values against $\left(N_{1}\right)_{60}$ (the corrected SPT blow number) pairs for cases in which liquefaction was or was not observed, a curve that bounds the condition can be drawn. Figure 1 is adapted from Seed et al (1984) which shows recommended boundary curves for various Fines Content (FC) associated with the SPT-based case histories. Idriss and Boulanger (2006) made a very comprehensive review on the modifications introduced in the past into, and made comparison through, these typical boundary curves shown in figure 2 .

Alternative methods for field evaluation of liquefaction potential include CPT-based and Vsbased procedures. Experimental studies by Olsen and Koester (1995); Olsen (1997); Robertson and Wride (1998); Suzuki et al (1995); Juang et al (1999, 2002, 2006); Toprak et al (1999), provided valuable information and insight into the CPTbased concept for practising engineers. Although liquefaction triggering correlation graphs based on shear wave velocity have been provided by various researchers (e.g., Andrus and Stokoe 2000) as mentioned by Seed et al (2003) and Idriss and Boulanger (2006), Vs-based correlation is less welldefined (more approximate) than either SPT- or CPT-based correlations.

\section{Deterministic models}

As discussed in the preceding sections, the common practice is to calculate the FS as the initial step in the evaluation process of safety in a structure. The second and complementary step in evaluating the safety requires the computation of the probability of failure using an appropriate performance function and parameters. The relation between random parameters, $x_{i}$, and performance function is expressed as:

$$
Z=f\left(x_{1}, x_{2}, \ldots, x_{n}\right) .
$$

The failure plane or boundary plane in the random parameter space can be expressed as:

$$
f\left(x_{1}, x_{2}, \ldots, x_{n}\right)=0 .
$$

This plane is a boundary between the safe and failure regions. If the performance function is solely based on the FS, then FS $\geq 1$ corresponds to nonliquefaction and FS $<1$ denotes the occurrence of liquefaction. This assessment is usually referred to as deterministic approach and may be simply expressed as $f(x)=\mathrm{CRR} / \mathrm{CSR}$.

\section{Cyclic shear stress ratio}

In the deterministic approach, CSR is usually calculated using Seed and Idriss (1971) relation:

$\mathrm{CSR}=\left(\frac{\tau_{\mathrm{av}}}{\sigma_{v}^{\prime}}\right)=0.65\left(\frac{a_{\mathrm{max}}}{g}\right)\left(\frac{\sigma_{v}}{\sigma_{v}^{\prime}}\right)\left(\frac{r_{d}}{\mathrm{MSF}}\right)$.

In fact CSR can be defined as the ratio of the equivalent cyclic shear stress developed during earthquake loading $\left(\tau_{\mathrm{av}}\right)$ to the effective normal stress during consolidation on any plane. In equation (3) $\sigma_{v}$ and $\sigma_{v}^{\prime}$ are referred as the total and effective stress respectively; $g$ is ground acceleration; and $a_{\max }$ is the peak ground acceleration. The term MSF in equation (3) is the earthquake magnitude scaling factor adopted by Seed and Idriss (1971) for adjusting the induced CSR during earthquake magnitude $M$ to an equivalent CSR for earthquake magnitude $M=7.5$. It is, therefore, defined as:

$$
\mathrm{MSF}=\frac{\mathrm{CSR}_{M}}{\mathrm{CSR}_{m=7.5}} .
$$

Youd and Idriss (1997) suggested a relatively different correlated relation for such adjustment which was initially adopted in this study. The relation is as follows:

$$
\mathrm{MSF}=\frac{10^{2.24}}{M_{w}^{2.56}}
$$

where $M_{w}$ is the earthquake moment magnitude. Idriss and Boulanger (2006) recommended the use of following relation for MSF:

$$
\begin{aligned}
& \mathrm{MSF}=6.9 \exp (-0.25 M)-0.058 \\
& \mathrm{MSF} \leq 1.8
\end{aligned}
$$


which was based on a re-evaluation of the relation expressed earlier by Idriss (1999) for MSF. Idriss and Boulanger (2006) also compared the re-evaluated values of MSF with those originally proposed by Seed and Idriss (1982) and other researchers. They observed some differences between these values and concluded that these differences were partly attributed to differences in the measured $r_{d}$ relations. They also stated that because MSF and $r_{d}$ relations are inter-related through their dependence on earthquake magnitude, the empirical derivation of MSF that rely on magnitude-independent $r_{d}$ relations, are lumping both effects of earthquake magnitude into the MSF parameter alone. Hence, they recommended that it is essential for $r_{d}$ and MSF relations to be used in the same combination in which they were derived.

The stress reduction coefficient, $r_{d}$, originally introduced by Seed and Idriss (1971), is a parameter which expresses the ratio of cyclic stress for a flexible soil column to cyclic stress for a rigid soil column. It measures the attenuation of peak shear stress with depth due to non-elastic behaviour of soil column as:

$$
r_{d}=\frac{\left(\tau_{\max }\right)_{d}}{\left(\tau_{\max }\right)_{r}}
$$

where $\left(\tau_{\max }\right)_{r}$ is the maximum shear stress for rigid body and $\left(\tau_{\max }\right)_{d}$ is the deformable body shear stress. It was initially found that $r_{d}$ reduces from a value of unity at the surface to typically between 0.3 and 0.7 at a soil depth of about $30 \mathrm{~m}$. Several empirical expressions for $r_{d}$ have been proposed by various researchers which are reviewed by Youd et al (2001). Some of them express the reduction factor, $r_{d}$, based on the depth of soil. Iwasaki et al (1978) expressed the following relation for stress reduction factor based on parametric site response analysis on alluvial deposits:

$$
r_{d}=1.0-0.015 Z
$$

In this study, $r_{d}$ was initially adopted based on the relation introduced by the National Center for Earthquake Engineering Research (NCEER) which is quoted here (Youd et al 2001):

\section{Cyclic shear resistance ratio}

In the original Seed and Idriss (1971) procedure, soil liquefaction resistance is expressed in terms of blow counts $\left(N_{1}\right)$ resulting from SPT and is characterized by cyclic resistance ratio (or simply CRR). The CRR, therefore, may be considered as the maximum CSR value that a soil layer can resist before liquefaction. The cyclic shear resistance ratio is also defined based on the in situ strength characteristics of soil. Seed et al (1984) developed an empirical graph, shown in figure 1, to define the CRR based on corrected standard penetration test results. Graphically, it is equivalent to CSR values with empirical parameters, such as $\left(N_{1}\right)_{60}$; the corrected blow counts. This graph predicts an appropriate and conservative boundary.

The curves in figure 1 have been approximated by Rauch (1997) using the following relation:

$$
\begin{aligned}
\mathrm{CRR}_{7.5}= & \frac{1}{34-\left(N_{1}\right)_{60}}+\frac{\left(N_{1}\right)_{60}}{135} \\
& +\frac{50}{\left[10\left(N_{1}\right)_{60}+45\right]^{2}}-\frac{1}{200} .
\end{aligned}
$$

It is to be noted that the above relation is only applied to $\left(N_{1}\right)_{60}$ values less than 30 and for $\left(N_{1}\right)_{60}$ values larger than 30 , it is reasonably assumed that the soil is adequately dense and hence not prone to liquefaction.

To consider the effect of fines content (FC) on CRR, the following relation was suggested by Seed et al (2001):

$$
\left(N_{1}\right)_{60 c s}=a+b\left(N_{1}\right)_{60},
$$

in which, $a$ and $b$ are constant parameters and $\left(N_{1}\right)_{60 c s}$ is the corrected blow counts for clean sands. The percentage of FC in sand, was used to define $a$ and $b$ as expressed in the following relations:

$$
a= \begin{cases}0.0 & \text { for } \mathrm{FC} \leq 5 \% \\ \exp \left[1.76-\left(190 / \mathrm{FC}^{2}\right)\right] & \text { for } 5 \%<\mathrm{FC}<35 \% \\ 5.0 & \text { for } \mathrm{FC} \geq 35 \%\end{cases}
$$

$$
r_{d}=\frac{\left(1-0.4113 Z^{0.5}+0.04052 Z+0.001753 Z^{1.5}\right)}{\left(1-0.4177 Z^{0.5}+0.05729 Z-0.006205 Z^{1.5}+0.001210 Z^{2}\right)}
$$

In this relation, $Z$ is the depth of any soil layer. 
$b= \begin{cases}1.0 & \text { for } \mathrm{FC} \leq 5 \% \\ {\left[0.99+\left(\mathrm{FC}^{1.5} / 1000\right)\right]} & \text { for } 5 \%<\mathrm{FC}<35 \% \\ 1.2 & \text { for } \mathrm{FC} \geq 35 \%\end{cases}$

Using equations (12) and (13), an equivalent value of $\left(N_{1}\right)_{60}$ for clean sand is obtained.

It is to be noted that the CRR may also be approximated using a different relation introduced by Blake (cited in Youd and Idriss 1997) or also through a relation developed by Robertson and Wride (1998) based on CPT.

Recent adjustments for FC suggest the new correlation's regressed correction for the effect of FC. As reported and discussed by Seed et al (2003), reviews showed slight differences for the correlations manifested as shifted curves in the graph when compared with previous correlation graphs. Based on the overall (regressed) correlation, the energy, procedure, and overburden correlated $N$-values $\left(N_{1}\right)_{60}$, are further corrected by Seed et al (2003) for FC as:

$$
\left(N_{1}\right)_{60 c s}=\left(N_{1}\right)_{60} \times C_{\text {fines }},
$$

where $C_{\text {fines }}$, the FC correction was regressed as part of the Bayesian updating analysis. The fines correction is equal to 1.0 for $\mathrm{FC} \leq 5 \%$ and reaches maximum limiting value for $\mathrm{FC} \geq 35 \%$. The regressed relationship for $C_{\text {fines }}$ was obtained by Seed et al (2003) as:

$$
\begin{aligned}
C_{\text {fines }}= & (1+0.004 \mathrm{FC})+0.05\left[\mathrm{FC} / N_{160}\right] \\
& 35 \% \geq \mathrm{FC} \geq 5 \% .
\end{aligned}
$$

Idriss and Boulanger (2006) also considered the effect of FC and used both SPT and CPT data in order to develop a consistent pair of liquefaction correlation for cases with $\mathrm{FC} \leq 5 \%$. The variation of $q_{C 1 N} /\left(N_{1}\right)_{60}$ ratio with $D_{r}$ was consistent with the expected differences in drainage conditions for these two in situ tests. Idriss and Boulanger (2006) incorporated these considerations and the revised CRR- $\left(N_{1}\right)_{60}$ relations. For cohesionless soils having $\mathrm{FC} \leq 5 \%$, the revised relation showed a relatively modest change to that proposed at the NCEER/NSF workshop. Further, the cases for cohesionless soils with FC $\geq 35 \%$ were plotted by Idriss and Boulanger (2006) along with the applicable curve agreed to at the NCEER/NSF workshop and new curve was also proposed. Several case history data points fell below the $\mathrm{FC} \geq 35 \%$ boundary curve agreed to at the NCEER/NSF workshop and they govern the position of the revised curve. In this regard, the revised boundary curves proposed by Idriss and Boulanger (2006) for cohesionless soils were expressed using the following relations:

$$
\left(N_{1}\right)_{60 c s}=\left(N_{1}\right)_{60}+\Delta\left(N_{1}\right)_{60}
$$

$\Delta\left(N_{1}\right)_{60}=\exp \left(1.63+\frac{9.7}{\mathrm{FC}+0.1}-\left(\frac{15.7}{\mathrm{FC}+0.1}\right)^{2}\right)$.

It is noted that equation (16) is similar to the relation expressed by equation (11).

\section{Proposed reliability analysis and optimization procedure}

In probability analysis, an appropriate way of evaluating for safety against liquefaction is the application of reliability index. This index, evaluates the safety better than the 'FS' itself since it involves detailed and statistical variations in strength and loading parameters whereas the FS approach is based on certain deterministic values. Furthermore, many geotechnical engineers believe that the 'FS' has a rather weak physical interpretation and the selection of a convincing value for ' $\mathrm{FS}$ ' is somewhat difficult. Instead, in a probability analysis based on reliability index, the uncertainties in stress and strength characteristics are effectively incorporated into calculations.

\subsection{Reliability index}

In geotechnical engineering problems, stress and strength are commonly, functions of several variables and hence direct integration techniques cannot be used to calculate the reliability index $(\beta)$. Also probability analysis methods such as FORM and FOSM are strongly based on theory, however, due to complexity of the governing equations oversimplified assumptions such as linearity of the performance function, independent soil parameters, infinite intrinsic correlation for other soil characteristics, and numerical estimations are involved for the calculation of reliability index and failure probability. These assumptions and estimations often lead to highly inaccurate results. Computeraided simulation methods are used in a vast variety of statistical analysis and engineering applications mainly because of their fast calculations. In these methods, the probability density function is simulated in order to obtain the performance function and hence the failure probability. Despite the advantages of these methods, it should be noted that simulation of a given model itself may be highly time consuming.

More powerful techniques such as AFOSM should be used to calculate $\beta$ (Ditleveson 1981; Juang et al 1999):

$$
\beta=\min _{X \in F} \sqrt{(X-m)^{T} C^{-1}(X-m)},
$$


Table 1. Random variables and their characteristics.

\begin{tabular}{lcccc}
\hline $\begin{array}{l}\text { Random } \\
\text { variable }\end{array}$ & $\begin{array}{c}\text { Index in } \\
\text { equation }(18)\end{array}$ & Mean & $\begin{array}{c}\text { Coefficient of variation } \\
\text { (Tautmann 1996; }\end{array}$ & $\begin{array}{c}\text { Distribution } \\
\text { function }\end{array}$ \\
\hline$\left(N_{1}\right)_{60 c s}$ & $X_{1}$ & 20 & 0.30 & Normal \\
$\sigma_{v}$ & $X_{2}$ & $*$ & 0.10 & Normal \\
$\sigma_{v}^{\prime}$ & $X_{3}$ & $*$ & 0.15 & Normal \\
$a_{\max }$ & $X_{4}$ & 0.36 & 0.15 & Normal \\
$M_{w}$ & $X_{5}$ & 6.3 & 0.05 & Normal \\
\hline
\end{tabular}

*Mean value at every given depth calculated, no specific value.

where $X, m$, and $C$ are the vector of random variable, vector of mean values, and covariance matrix, respectively.

The minimization should be carried over $F$ which belongs to the specific area of performance function corresponding to $G(X)<0$. As mentioned in the preceding section, in order to evaluate liquefaction potential the limit state function can be defined by $G(X)=(\mathrm{CRR} / \mathrm{CSR})-1$.

\subsection{Random variables}

In this study, 180 data records related to the area under investigation were collected. The sources of information and data collected are discussed in section 9. Considering the relations discussed in preceding sections, parameters $a_{\max }, M_{W}, \sigma_{v}, \sigma_{v}^{\prime}$, $\left(N_{1}\right)_{60}$ are all involved in the problem and each one is treated as a random variable. The first four parameters have high correlations which are considered in the calculation process.

$a_{\text {max }}$ can generally be estimated using so-called empirical acceleration attenuation formulas which express relation between the attenuated peak ground acceleration, $a_{\max }$, with the increasing epicentral or hypocentral distance, say $R$, for an earthquake of a given magnitude $M$. These attenuation relations are usually regressed through measured seismic data including $a_{\max }, M$ and $R$ using some functional forms.
Table 2. Correlation coefficients between the variables.

\begin{tabular}{lccccc}
\hline & $\left(N_{1}\right)_{60 c s}$ & $\sigma_{v}$ & $\sigma_{v}^{\prime}$ & $a_{\max }$ & $M_{w}$ \\
\hline$\left(N_{1}\right)_{60 c s}$ & 1.00 & 0.00 & 0.00 & 0.00 & 0.00 \\
$\sigma_{v}$ & 0.00 & 1.00 & 0.95 & 0.00 & 0.00 \\
$\sigma_{v}^{\prime}$ & 0.00 & 0.95 & 1.00 & 0.00 & 0.00 \\
$a_{\max }$ & 0.00 & 0.00 & 0.00 & 1.00 & 0.90 \\
$M_{w}$ & 0.00 & 0.00 & 0.00 & 0.90 & 1.00 \\
\hline
\end{tabular}

Different relations have been proposed by various researchers for attenuation of $a_{\max }$. Donovan (1972), for example, proposed the following relation for a variety of regions around the world, excluding California in USA, as:

$$
a_{\max }=\frac{1.1 \exp (0.5 M)}{(R+25)^{1.32}},
$$

where $a_{\max }$ is the horizontal peak ground acceleration $(g) ; R$ is the hypocentral distance $(\mathrm{km})$; and $M$ is the local Richter magnitude.

The coefficient of variation for $\sigma_{v}, \sigma_{v}^{\prime}$ variables is estimated based on variations observed in the soil density, which was in the range $15-22 \mathrm{KN} / \mathrm{m}^{3}$. Table 1 presents a summary of statistical characteristics of the data collected and the variables selected for each dataset.

Equation (18) can be expanded in the following form:

$$
\begin{aligned}
\beta^{2}= & \min _{G(X)<0}\left\{\left[\frac{\left(X_{1}-m_{1}\right)^{2}}{\sigma_{1}^{2}}\right]+\left[\frac{\left(X_{2}-m_{2}\right)^{2}}{\sigma_{2}^{2}}-2 \frac{\left(X_{2}-m_{2}\right)\left(X_{3}-m_{3}\right) \rho_{23}}{\sigma_{2} \sigma_{3}}+\frac{\left(X_{3}-m_{3}\right)^{2}}{\sigma_{3}^{2}}\right]\left(\frac{1}{1-\rho_{23}^{2}}\right)\right. \\
& \left.+\left[\frac{\left(X_{4}-m_{4}\right)^{2}}{\sigma_{4}^{2}}-2 \frac{\left(X_{4}-m_{4}\right)\left(X_{5}-m_{5}\right) \rho_{45}}{\sigma_{4} \sigma_{5}}+\frac{\left(X_{5}-m_{5}\right)^{2}}{\sigma_{5}^{2}}\right]\left(\frac{1}{1-\rho_{45}^{2}}\right)\right\} \\
& \left.+\left[\frac{\left(X_{4}-m_{4}\right)^{2}}{\sigma_{4}^{2}}-2 \frac{\left(X_{4}-m_{4}\right)\left(X_{5}-m_{5}\right) \rho_{45}}{\sigma_{4} \sigma_{5}}+\frac{\left(X_{5}-m_{5}\right)^{2}}{\sigma_{5}^{2}}\right]\left(\frac{1}{1-\rho_{45}^{2}}\right)\right\} .
\end{aligned}
$$




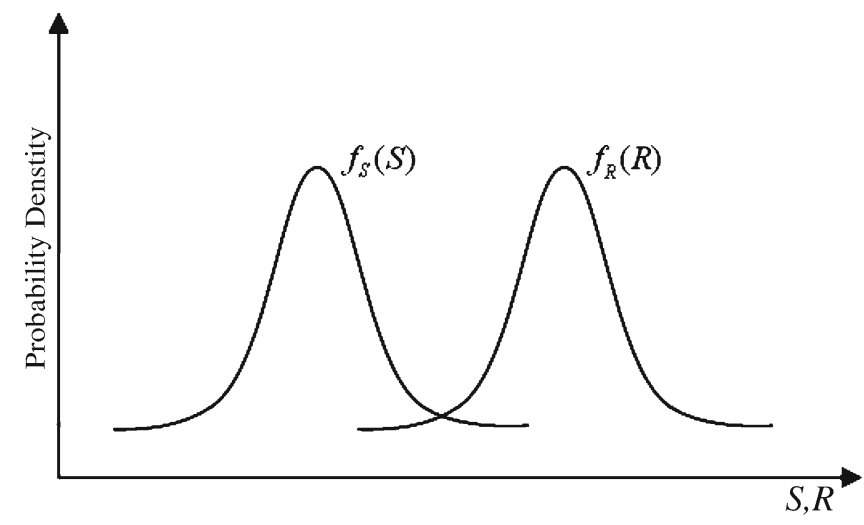

Figure 3. Probability density variation with $R$ and $S$.

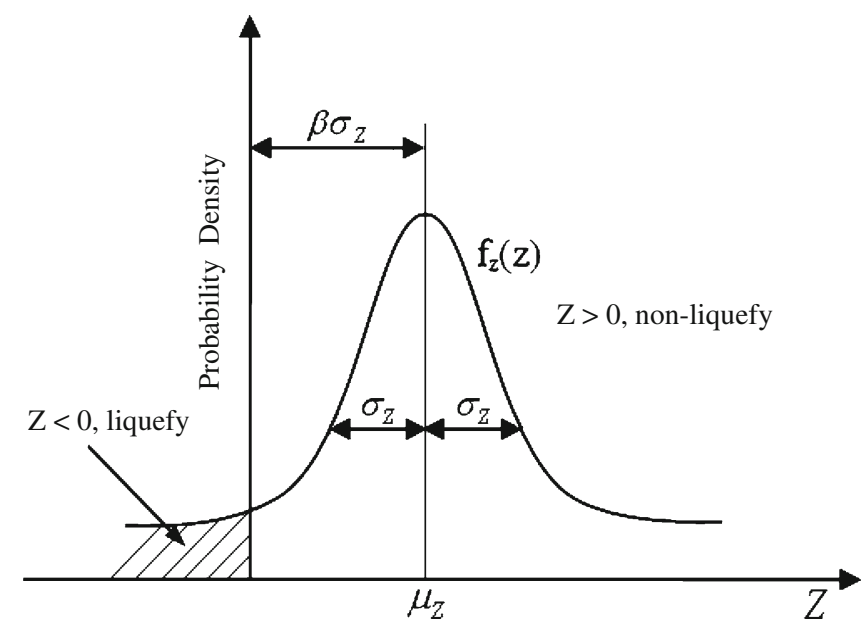

Figure 4. Probability of density variation with $Z$.

Table 1 contains the selected $X_{i}$ variables of equation (20), while $\rho_{23}$ and $\rho_{45}$ are correlation coefficients between $X_{2}, X_{3}$ and $X_{4}, X_{5}$, respectively. These correlation coefficients are given in table 2. It can be further discussed that if random variables are large in number, dependent and that the limit state function is nonlinear, then $\beta$ is preferably calculated by AFOSM method while failure probability is obtained.

\subsection{Reliability index correlation with liquefaction potential}

The performance function is one of the primary factors in a reliability analysis. Considering some uncertainties involved in determination of CRR and CSR, they are represented by $R$ and $S$, respectively and treated as random variables with a normal distribution. Then, the performance function can be defined as $Z=R-S$ which also has a normal distribution. It follows that if $Z<0$, failure and liquefaction are probable. This is graphically summarized in figure 3 (Hwang et al 2004).

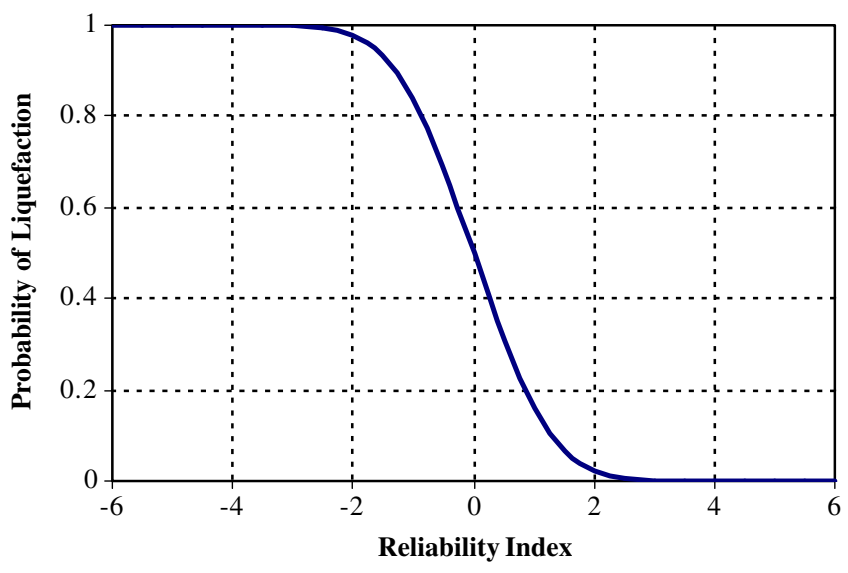

Figure 5. Probability of liquefaction variation with reliability index.

The probability density function and the cumulative probability function are defined by $f_{z}(z)$ and $F_{z}(z)$, respectively. It follows that the liquefaction probability $\left(P_{L}\right)$ can be presented by the area covered under the curve where $Z=R-S$ and hence:

$$
P_{L}=(Z<0)=\int_{-\infty}^{0} f_{z}(z) d z=F_{Z}(0) .
$$

In figure 4 , the liquefaction probability is shown by a dashed area under the probability density function curve $f_{z}(z)$. The mean and standard deviation parameters related to $R$ and $S$ are shown by $\mu_{R}, \mu_{S}$ and $\sigma_{R}, \sigma_{S}$, respectively. Therefore, the mean $\left(\mu_{Z}\right)$, standard deviation $\left(\sigma_{Z}\right)$, and covariance coefficient $\left(\delta_{Z}\right)$ in function $Z$ are calculated as follows:

$$
\begin{gathered}
\mu_{Z}=\mu_{R}-\mu_{S}, \\
\sigma_{Z}=\sqrt{\sigma_{R}^{2}+\sigma_{S}^{2}}, \\
\delta_{Z}=\frac{\mu_{Z}}{\sigma_{Z}}=\frac{\mu_{R}-\mu_{S}}{\sqrt{\sigma_{R}^{2}+\sigma_{S}^{2}}} .
\end{gathered}
$$

The reliability index, $\beta$, is defined as the inverse of $\delta_{Z}$ (i.e., the covariance coefficient):

$$
\beta=\frac{1}{\delta_{Z}}=\frac{\sigma_{Z}}{\mu_{Z}} .
$$

This index is used to calculate the liquefaction probability $\left(P_{L}\right)$ which can now be defined as:

$$
P_{L}=\int_{-\infty}^{0} f_{z}(z) d z=\int_{-\infty}^{0} \frac{1}{\sqrt{2 \pi} \sigma_{Z}} e^{-\frac{1}{2}\left(\frac{Z-\mu_{Z}}{\sigma_{Z}}\right)^{2}} d z .
$$

With new variable $t=\left(Z-\mu_{Z}\right) / \sigma_{Z}$, one obtains:

$$
P_{L}=\int_{-\infty}^{-\frac{\mu_{Z}}{\sigma_{Z}}} \frac{1}{\sqrt{2 \pi}} e^{-\frac{t^{2}}{2}} d z=\Phi\left(-\frac{\mu_{Z}}{\sigma_{Z}}\right)
$$




$$
P_{L}=\Phi(-\beta)=1-\Phi(\beta)
$$

Figure 5 shows plot of equation (27) for reliability indices and the corresponding probabilities which vary between zero and unity.

\subsection{Minimization of the reliability index function}

Various numerical techniques may be employed to minimize the reliability index function. Among them, GA is an appropriate and sophisticated method which is adopted in this study to carry out the optimization procedure (Goldberg 1989; Krishnakumar and Goldberg 1992).

\section{Genetic algorithm}

Genetic algorithm is a numerical search technique which is analogous to the process of natural selection in biology according to Darwin. The evolution of population in nature occurs according to the principles of natural selection and survival of the fittest. Based on these principles, individuals in a population compete with each other. Those who best fit their environment have the most chance of

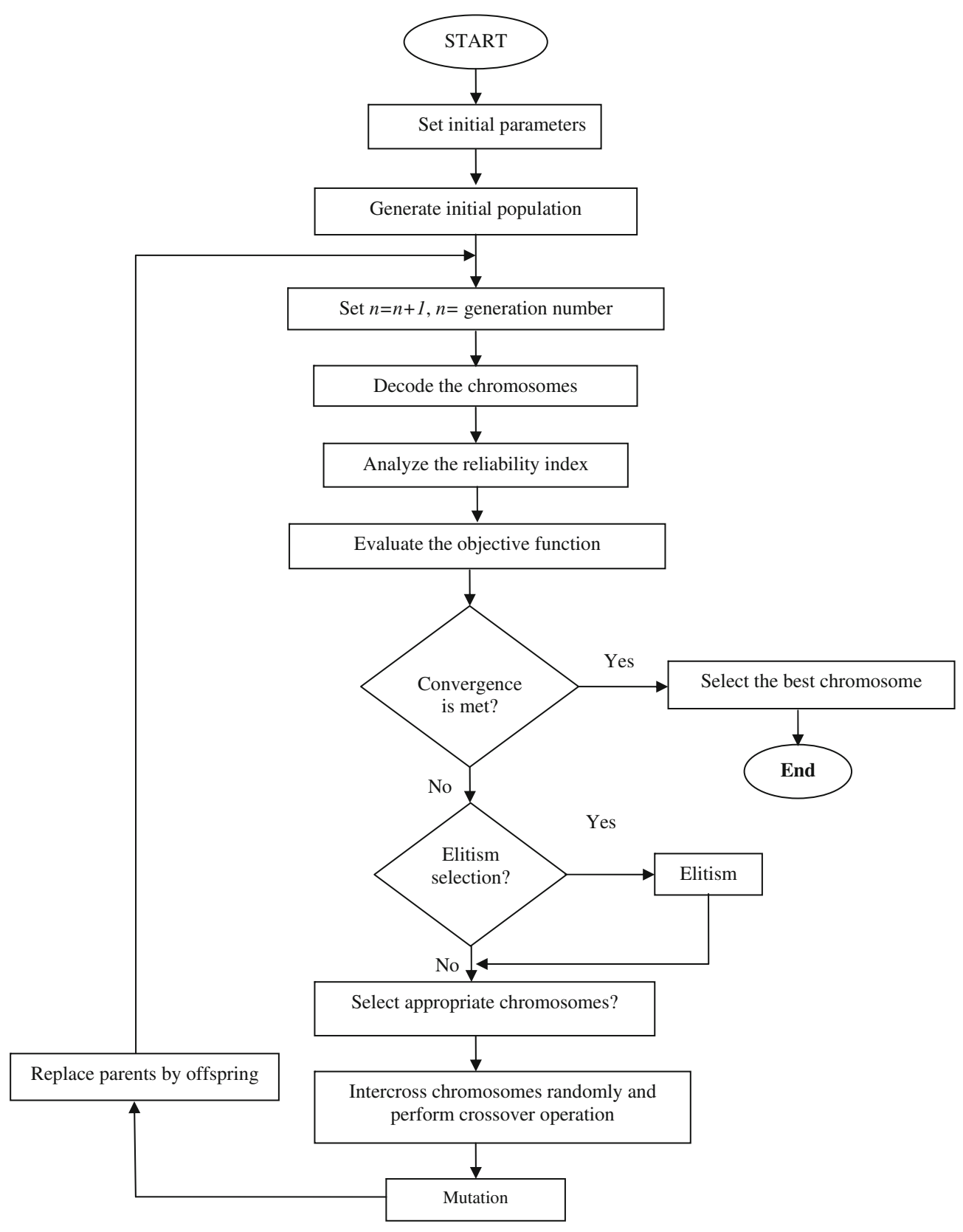

Figure 6. Flowchart of GA. 
survival and will have relatively more offspring in the next generation. Conversely, individuals with poor performance produce fewer offspring and may even vanish and produce no offspring at all. Hence, characteristics of the most successful individuals in surviving will spread to an increasing part of the population.

In summary, GA works with a population of individuals each representing a possible solution (answers) for a given problem (McCully and Bleobaum 1996). The population of individuals evolves through mating between members. Most optimization techniques require derivatives of the problem functions, whereas in GA method, only information related to each member is of prime importance. While derivation of the functions, in many cases, is not obtained in a straightforward manner, in general, GA methods do not deal with the problem details. Therefore, a GA method is more flexible than any other optimization process especially because the algorithm benefits form coded and binary variables which are suitable for computer programming. A flowchart based on the principles discussed above is shown in figure 6 representing GA cycles which lead to convergence.

It should be mentioned that in GA process some parameters affect the convergence rate. For example, population size, mutation, and crossing are such parameters. Hence, in order to minimize the effect of these parameters on convergence rate, a sensitivity analysis is usually performed prior to the main GA analysis through which an appropriate range for the variables is introduced. Then, one of the variables is assumed to be the prime variable, while the others remain constant. Then, the rate of convergence is observed for that variable over the predefined range. The process is continued for each variable until a suitable range is established for each variable. The sensitivity analysis conducted for minimization of the function of reliability index has led to the following appropriate values to be applied for GA analysis: probability of crossover, $\mathrm{Pc}=0.65$, initial population, $\mathrm{Npop}=50$, mutation probability, $\mathrm{Pm}=0.025$, and maximum

Table 3. Operation description and related parameter in GA cycle.

\begin{tabular}{|c|c|c|c|}
\hline Operation & Description & $\begin{array}{l}\text { Related } \\
\text { parameter }\end{array}$ & Parameter description \\
\hline Population & $\begin{array}{l}\text { GA starts with choice of some individ- } \\
\text { uals (potential answers for the prob- } \\
\text { lem) generated using a random genera- } \\
\text { tor. The set of chosen values are called } \\
\text { population and the first set is referred to } \\
\text { as 'initial population'. Members of the } \\
\text { population are chosen to act as parents } \\
\text { to produce children for next generation } \\
\text { (next set of potential answers). }\end{array}$ & Npop & $\begin{array}{l}\text { The size of the population is the number of the } \\
\text { members that constitute the population. It is } \\
\text { shown usually by parameter 'Npop'. The num- } \\
\text { ber of initial population is a matter of concern } \\
\text { and is usually adopted based on the sensitivity } \\
\text { analysis. In this study, it is selected as Npop = } \\
50 \text { after sensitivity analysis. }\end{array}$ \\
\hline Generation & $\begin{array}{l}\text { In each cycle in GA, when the number } \\
\text { of the produced children (new potential } \\
\text { answers) is equal to the size of popula- } \\
\text { tion }(\mathrm{Np}) \text {, then one generation is formed. }\end{array}$ & MaxGen & $\begin{array}{l}\text { Maximum number of generation 'MaxGen' is } \\
\text { a predefined number which is a criterion that } \\
\text { checks the termination process. When MaxGen } \\
\text { is reached, the GA process is terminated even if } \\
\text { the convergence criterion is not satisfied. }\end{array}$ \\
\hline Crossover & $\begin{array}{l}\text { Operates on two chromosomes and } \\
\text { swaps some of their genes which creates } \\
\text { two new chromosomes representing two } \\
\text { new individuals. In GA context, these } \\
\text { new individuals may be considered as } \\
\text { new potential answers. }\end{array}$ & $\mathrm{Pc}$ & $\begin{array}{l}\text { Crossover operation is carried in a probabilis- } \\
\text { tic manner and hence a probability number is } \\
\text { assigned to it which is referred to as 'crossover } \\
\text { probability' or 'Pc'. Similar to Npop, sensitivity } \\
\text { analysis may be carried to select the best value } \\
\text { for Pc or it may be adopted based on some other } \\
\text { inference. }\end{array}$ \\
\hline Mutation & $\begin{array}{l}\text { This operator occasionally changes } \\
\text { the produced children (new potential } \\
\text { answers) based on probabilistic prin- } \\
\text { ciples by exchanging some of their } \\
\text { genes and preserves the diversity of the } \\
\text { population (set of potential answers) } \\
\text { by introducing new members and also } \\
\text { prevents the local optimums. }\end{array}$ & $\mathrm{Pm}$ & $\begin{array}{l}\text { Mutation occurs probabilistically according to a } \\
\text { chosen rate which, again, may be adopted based } \\
\text { on sensitivity analysis. It implies on the proba- } \\
\text { bility for the mutation of a gene usually indexed } \\
\text { by binary numbers ' } 0 \text { ' and ' } 1 \text { ' in the chromo- } \\
\text { somes' string. If the total number of handled } \\
\text { genes is assumed to be } n \text {, then } \mathrm{Pm} \times n \text { genes are } \\
\text { mutated. }\end{array}$ \\
\hline
\end{tabular}


number of generation, MaxGen $=40$. These parameters are also shown in table 3, where a very concise description of the GA operations and related parameters is also presented.

\subsection{Variables and constraints}

Variables in the problem under consideration are listed in table 1. As mentioned earlier, to calculate the probability of liquefaction, a specific relation as $G(X)=(\mathrm{CRR} / \mathrm{CSR})-1<0$ exists which is regarded as a constraint. Furthermore, the range of each variable should also be applied as an additional constraint. In general, the problem constraints are introduced as:

$$
\frac{g_{i}}{g_{a}}-1<0, \quad i=1,2, \ldots, n,
$$

in which $g_{i}$ and $g_{a}$ may have the values of CRR and CSR, respectively at any depth. Therefore, equation (29) can be represented as follows:

$$
\frac{\mathrm{CRR}}{\mathrm{CSR}}-1<0 \text {. }
$$

\subsection{Objective and adjunct function}

The objective function is the reliability index $(\beta)$, however, since GA is primarily formulated for unconstrained functions, in order to use the method for constrained functions, the set of objective functions and their corresponding constraints should be transformed into a set of equivalent free functions also referred to as adjunct functions. The most common method to form an adjunct function is to add a penalty function to the original

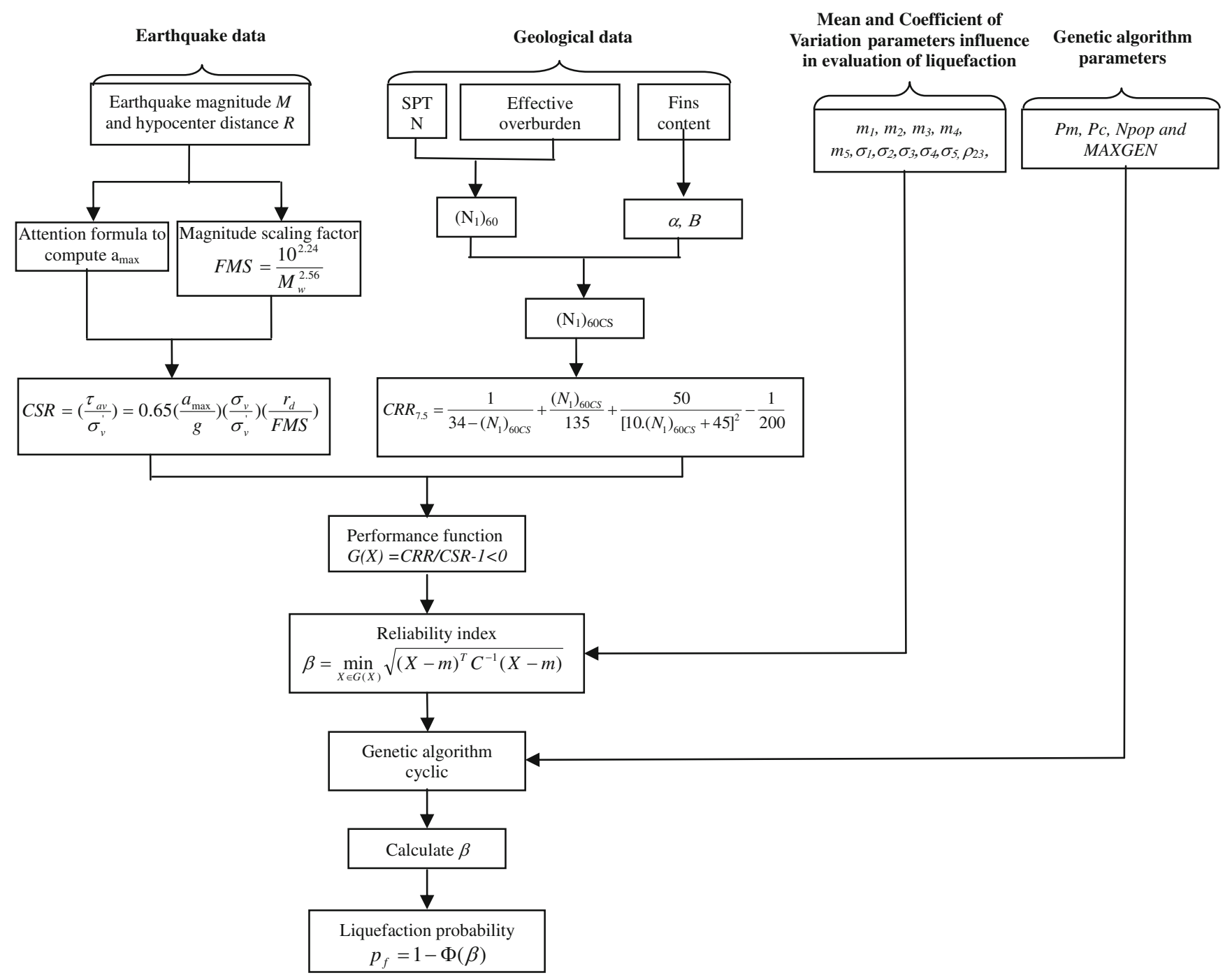

Figure 7. Flowchart of the proposed concept in the current study. 
Table 4. Name and characteristics of active faults around the site studied.

\begin{tabular}{llccccc}
\hline No. & Fault name & $\begin{array}{c}\text { Fault length } \\
(\mathrm{km})\end{array}$ & $\begin{array}{c}\text { Effective length } \\
(\mathrm{km})\end{array}$ & $\begin{array}{c}\text { Distance } \\
(\mathrm{km})\end{array}$ & $\begin{array}{c}a_{\max } \\
(\mathrm{g})\end{array}$ & $\begin{array}{c}\text { Magnitude } \\
(M)\end{array}$ \\
\hline 1 & Khazar & 250 & 130 & 13 & 0.28 & 7.7 \\
2 & North Alborz & 360 & 145 & 23 & 0.19 & 7.8 \\
3 & Babol fault line & 50 & 18 & 10 & 0.32 & 6.3 \\
\hline
\end{tabular}

objective equations. Therefore, the equivalent free function can be written in the form as follows:

$$
\phi=\beta+R_{P} \sum_{i=1}^{n g}\left[\max \left(\frac{g_{i}}{g_{a}}-1.0\right)\right]^{2},
$$

or

$$
\phi=\beta+R_{P} \sum_{i=1}^{n g}\left[\max \left(\frac{\mathrm{CRR}}{\mathrm{CSR}}-1.0\right)\right]^{2},
$$

where $\phi, \beta, R_{P}$, are the adjunct function, the objective function (i.e., reliability index), and the coefficient of penalty function, respectively; $n_{g}$ is the number of generations. The coefficient of penalty function is calculated based on the following relation (Goldberg 1989):

$$
R_{p}=r_{1}\left[1+r\left(i_{\text {ger }}-1\right)\right] \leq 4 r_{1},
$$

where $r_{1}$ is the base coefficient of penalty function (selected as 25) and $i_{\text {ger }}$ is a counter used to number each successive generation; while $r$ is a constant taken to be 0.2 .

Stages of current investigations as well as sequences of GA process are presented in figure 7 .

\section{Application}

As an application of the proposed method, the city of Babolsar is investigated for liquefaction potential. The city is located at east $52^{\circ} 39^{\prime}$ longitude and north $36^{\circ} 43^{\prime}$ latitude and is situated on the southern coast of the Caspian Sea. Highly active and causative faults exist in and around the city, some are listed in table 4 . Others in the region are the Caspian, Amol and Nour faults. It is of

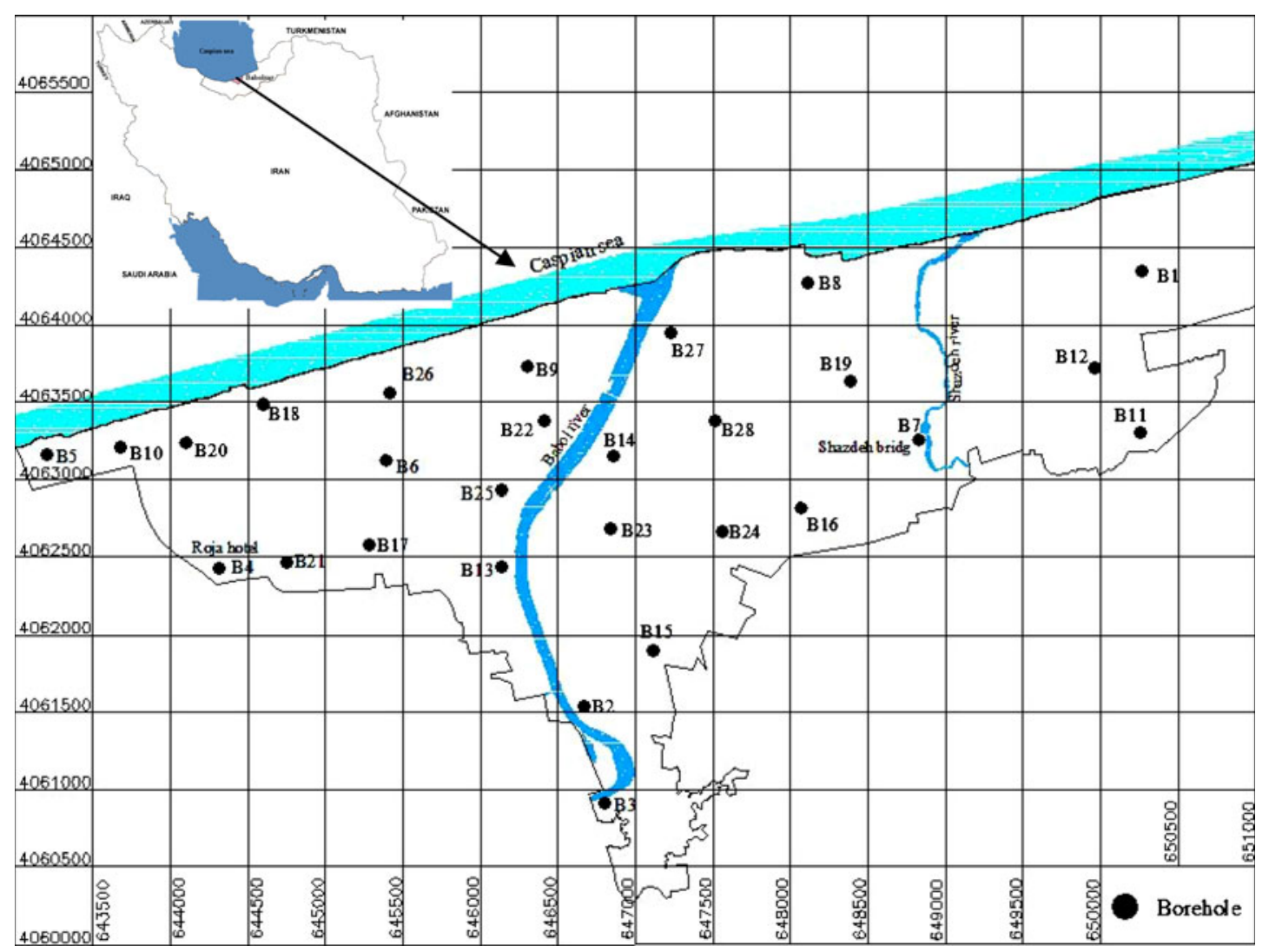

Figure 8. Area of study and borehole locations. 
Table 5. Summary of the information and calculations of liquefaction potential in the region.

\begin{tabular}{|c|c|c|c|c|c|c|c|c|c|c|c|c|c|}
\hline Case & $\begin{array}{l}\text { Borehole } \\
\text { number }\end{array}$ & $\begin{array}{l}\text { depth } \\
(\mathrm{m})\end{array}$ & $\begin{array}{c}\text { Soil } \\
\text { classification }\end{array}$ & $\begin{array}{c}\sigma_{v} \\
\left(\mathrm{~T} / \mathrm{m}^{2}\right)\end{array}$ & $\begin{array}{c}\sigma_{v}^{\prime} \\
\left(\mathrm{T} / \mathrm{m}^{2}\right)\end{array}$ & $\left(N_{1}\right)_{60 c s}$ & $a_{\max }$ & $M_{w}$ & CRR & CSR & FS & $\beta$ & $\begin{array}{l}P_{L} \\
(\%)\end{array}$ \\
\hline 1 & B1 & 18.0 & $\mathrm{SP}-\mathrm{SM}$ & 36.00 & 19.00 & 22 & 0.36 & 6.3 & 0.25 & 0.19 & 0.30 & 1.18 & 12 \\
\hline 2 & B3 & 4.0 & SP & 8.00 & 6.00 & 7 & 0.36 & 6.3 & 0.09 & 0.19 & 0.45 & -1.90 & 97 \\
\hline 3 & B4 & 4.0 & $\mathrm{SM}$ & 7.82 & 6.59 & 12 & 0.36 & 6.3 & 0.13 & 0.17 & 0.77 & -0.75 & 77 \\
\hline 4 & B6 & 6.0 & $\mathrm{SM}$ & 11.82 & 8.59 & 20 & 0.36 & 6.3 & 0.21 & 0.20 & 1.09 & 0.65 & 26 \\
\hline 5 & B8 & 7.0 & $\mathrm{SP}$ & 14.00 & 9.00 & 8 & 0.36 & 6.3 & 0.10 & 0.22 & 0.43 & -1.80 & 96 \\
\hline 6 & B15 & 11.0 & $\mathrm{SP}-\mathrm{SM}$ & 21.82 & 13.59 & 22 & 0.36 & 6.3 & 0.24 & 0.21 & 1.12 & 0.86 & 19 \\
\hline 7 & B28 & 16.0 & $\mathrm{SP}-\mathrm{SM}$ & 31.82 & 18.59 & 13 & 0.36 & 6.3 & 0.14 & 0.19 & 0.74 & -0.73 & 77 \\
\hline 8 & B2 & 3.5 & $\mathrm{SP}$ & 7.04 & 5.04 & 17 & 0.36 & 6.3 & 0.18 & 0.20 & 0.87 & -0.10 & 54 \\
\hline 9 & B13 & 16.0 & SP-SM & 32.00 & 22.69 & 15 & 0.36 & 6.3 & 0.16 & 0.15 & 1.03 & 0.30 & 38 \\
\hline 10 & B24 & 3.0 & SP & 4.53 & 3.33 & 21 & 0.36 & 6.3 & 0.22 & 0.20 & 1.11 & 0.75 & 23 \\
\hline 11 & B26 & 4.5 & $\mathrm{SP}-\mathrm{SM}$ & 7.05 & 4.35 & 5 & 0.36 & 6.3 & 0.07 & 0.24 & 0.31 & -2.53 & 99 \\
\hline 12 & B12 & 12.0 & SP & 23.37 & 12.85 & 18 & 0.36 & 6.3 & 0.19 & 0.23 & 0.82 & -0.15 & 56 \\
\hline 13 & B23 & 4.0 & SP & 7.80 & 6.35 & 12 & 0.36 & 6.3 & 0.13 & 0.18 & 0.72 & -0.90 & 82 \\
\hline 14 & B17 & 17.0 & $\mathrm{SM}$ & 34.19 & 18.69 & 21 & 0.36 & 6.3 & 0.22 & 0.19 & 1.17 & 1.00 & 16 \\
\hline 15 & B11 & 10.0 & $\mathrm{SP}-\mathrm{SM}$ & 19.82 & 12.59 & 20 & 0.36 & 6.3 & 0.21 & 0.21 & 1.00 & 0.50 & 31 \\
\hline 16 & B5 & 18.5 & $\mathrm{SM}$ & 33.60 & 15.10 & 16 & 0.36 & 6.3 & 0.17 & 0.20 & 0.85 & 0.00 & 50 \\
\hline 17 & B9 & 6.5 & $\mathrm{SM}$ & 13.00 & 9.50 & 14 & 0.36 & 6.3 & 0.15 & 0.20 & 0.78 & -0.70 & 76 \\
\hline 18 & B10 & 3.0 & $\mathrm{SP}-\mathrm{SM}$ & 6.00 & 4.50 & 13 & 0.36 & 6.3 & 0.14 & 0.20 & 0.71 & -0.88 & 81 \\
\hline 19 & B18 & 11.0 & $\mathrm{SP}-\mathrm{SM}$ & 22.00 & 14.00 & 9 & 0.36 & 6.3 & 0.11 & 0.21 & 0.52 & -1.59 & 94 \\
\hline 20 & B16 & 5.0 & $\mathrm{SP}$ & 10.00 & 7.50 & 19 & 0.36 & 6.3 & 0.21 & 0.19 & 1.08 & 0.62 & 27 \\
\hline
\end{tabular}

prime importance to investigate the earthquake hazards especially with regard to liquefaction, since the city overlies the saturated sand deposits (Shahpasandzadeh and Zare 1995; Haeri and Zolfaghari 1993).

In situ and laboratory tests for a relatively fine grid, $500 \times 500 \mathrm{~m}^{2}$ cells as shown in figure 8 , were carried for the region in order to evaluate the liquefaction potential. SPT was conducted in many boreholes located in the area as shown in the map. Information related to some other boreholes were gathered from various available sources especially those published by BHRC, IIEES, Building
Code 2800, etc. Others include those reported by Shahpasandzadeh and Zare (1995) and also by Haeri and Zolfaghari (1993).

Borehole depth varied from 15 to $40 \mathrm{~m}$ while water level in the region, based on borehole observation, varied in the range of $0.5-3 \mathrm{~m}$. The average depth of in situ tests was about $20 \mathrm{~m}$. Boring operations were conducted using the rotary drilling method. During the drilling operation, changes in soil layers as well as the water level were observed and registered. At different depths of the boreholes, soil samples were taken and sent to the soil lab for further analysis (Afzalirad 2006).


Figure 9. A simplified geotechnical profile and result of liquefaction for borehole B4. 
Table 6. Liquefaction likelihood classification by Chen and Juang (2000).

\begin{tabular}{|c|c|c|}
\hline Class & $\begin{array}{l}\text { Probability of } \\
\text { liquefaction }\left(P_{L}\right)\end{array}$ & Description of likelihood \\
\hline 1 & $P_{L}<15$ & $\begin{array}{l}\text { Almost certain that it will } \\
\text { not liquefy }\end{array}$ \\
\hline 2 & $15 \leq P_{L}<35$ & Unlikely to liquefy \\
\hline 3 & $35 \leq P_{L}<65$ & $\begin{array}{l}\text { Liquefaction and no liquefaction } \\
\text { are equally likely }\end{array}$ \\
\hline 4 & $65 \leq P_{L}<85$ & Very likely to liquefy \\
\hline 5 & $P_{L} \geq 85$ & $\begin{array}{l}\text { Almost certain that it will } \\
\text { liquefy }\end{array}$ \\
\hline
\end{tabular}

\section{Results and discussion}

As mentioned earlier, a dataset including approximately 180 records related to 28 boreholes located at different points and depths have been processed and analysed for liquefaction potential. In each case, the values of CSR, CRR, reliability indices and the probability of liquefaction occurrence were calculated continuously at all depths. For this purpose, equations (3), (10), (11) and (27) have been used in the subsequent manner while FS is also deterministically calculated. Updated versions of the correlated relations, quoted in preceding sections, were used in the course of calculations whenever possible with regard to obtaining improved results.

A relatively large volume of the calculated results was accumulated which cannot be fully quoted here. However, a summary of the information available and the related calculations are presented in table 5. A typical geotechnical profile as well as the result for liquefaction potential is presented in figure 9 for borehole B4. These were selected for a detailed discussion of the results and especially on those of utmost interest.

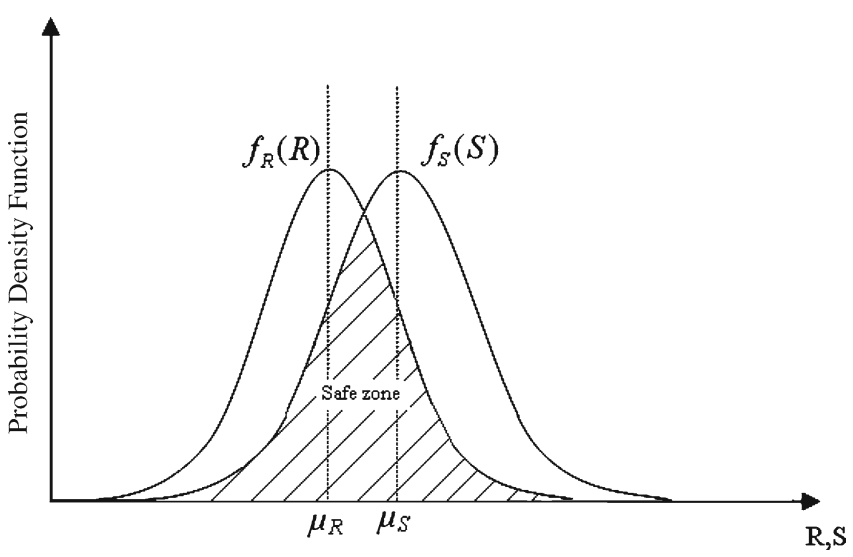

Figure 10. Safe zone with FS less than unity.
One of the most dominant terms in engineering especially in geotechnical is the FS and the related implications. Many engineers try to establish relations between the probability of failure and the FS. The former is based on the probabilistic approach in engineering problems whereas the latter is a deterministic factor even if it has been quantified based on probabilistic parameter.

Consider a general definition for $\mathrm{FS}$ as $\mathrm{FS}=\bar{R} / \bar{S}$ in which $\bar{R}$ and $\bar{S}$ are the average capacity and the structure response respectively. It may be regarded generally as a representation for structural safety but it fails to give a reasonable answer whenever uncertainties in $\bar{R}$ and/or $\bar{S}$ exist. It is to be mentioned that if a variable is not random and is deterministically defined, then its variance is zero. It further implies that if all other variables are similarly determined, the central FS represents a safe


Figure 11. Factor of safety and probability of liquefaction variations with depth in boreholes (located at Roja Hotel and Shahzadeh Bridge). 
situation but it does not consider the uncertainties in the $\bar{R}$ and/or $\bar{S}$. Conversely, if a central FS is assumed for a structure, any variation in probability density function of $\bar{R}$ and/or $\bar{S}$ results in different probability of failure. This may be exemplified by the data on rows 8 and 16 as well as rows 9 and 15 of table 5 .

The liquefaction likelihood classification introduced by Chen and Juang (2000) shown in table 6 is adopted for further discussion on the data and results are shown in table 5 . As can be seen from table 5, the FS related to row 9 is greater than unity, which implies no non-occurrence of liquefaction at the point referred. However, at the same point, the probability of liquefaction calculated based on the proposed method is $38 \%$, which according to Chen and Juang (2000) classification is presented in table 6 , for this point liquefaction occurrence is probable.

On rows 8 and 16, one can also observe that FS are 0.87 and 0.85 , respectively, while the related probabilities of liquefaction occurrence are $54 \%$ and $50 \%$ correspondingly. Therefore, greater FS does not necessarily mean a safer zone or low risk of failure. Similar trends can be seen in rows 9 and 15 and similar conclusion may be drawn. Therefore, a low FS does not necessarily mean the failure (liquefaction occurrence). The probability of failure may be contained in an acceptable range even if the FS is relatively low as shown in figure 10 .

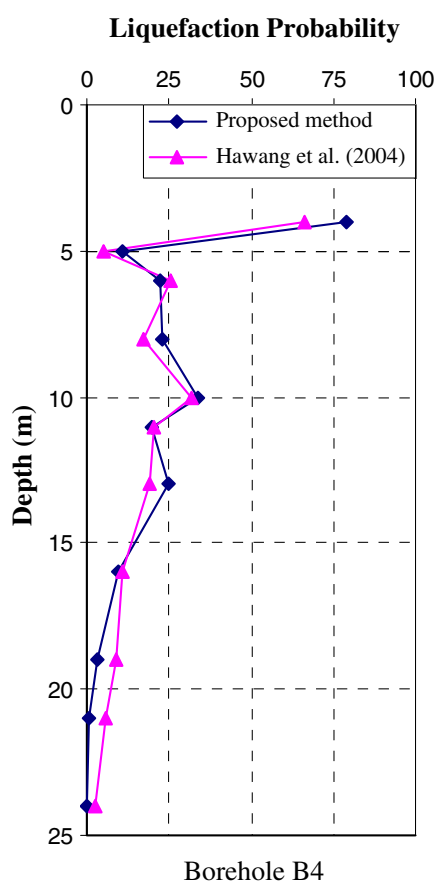

Liquefaction Probability

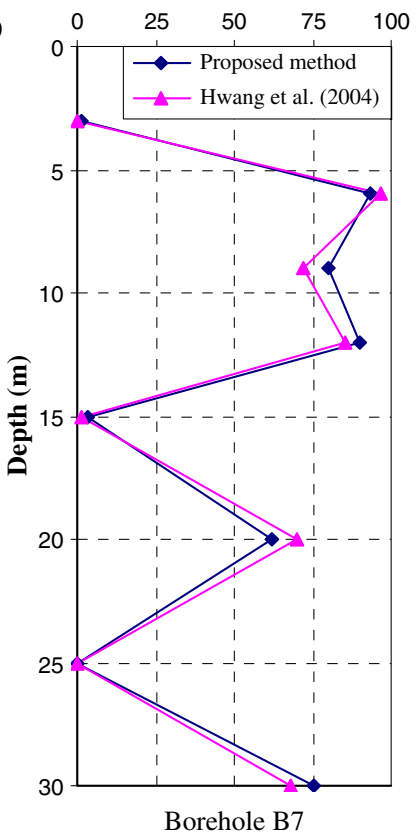

Figure 12. Comparison of proposed relation with Hwang et al (2004) relation.

A general conclusion may be drawn based on discussions given in preceding sections, in which a reduction in FS results in an increase in probability of failure irrespective of the method of calculation used for the FS. It can be seen that by

Table 7. Summary of comparison made between proposed models with Hwang et al (2004) relation.

\begin{tabular}{|c|c|c|c|c|c|}
\hline \multirow[b]{2}{*}{ Case } & \multirow[b]{2}{*}{$\left(N_{1}\right)_{60 c s}$} & \multirow[b]{2}{*}{ CSR } & \multicolumn{2}{|c|}{$P_{L}(\%)$} & \multirow[b]{2}{*}{ Error } \\
\hline & & & Proposed method & Hwang et al (2004) & \\
\hline 1 & 22 & 0.19 & 12 & 13 & 0.08 \\
\hline 2 & 7 & 0.19 & 97 & 92 & 0.05 \\
\hline 3 & 12 & 0.17 & 77 & 66 & 0.14 \\
\hline 4 & 20 & 0.20 & 26 & 26 & 0.00 \\
\hline 5 & 8 & 0.22 & 96 & 94 & 0.02 \\
\hline 6 & 22 & 0.21 & 19 & 18 & 0.05 \\
\hline 7 & 13 & 0.19 & 77 & 69 & 0.10 \\
\hline 8 & 17 & 0.20 & 54 & 46 & 0.15 \\
\hline 9 & 15 & 0.15 & 38 & 34 & 0.11 \\
\hline 10 & 21 & 0.20 & 23 & 20 & 0.13 \\
\hline 11 & 5 & 0.24 & 99 & 98 & 0.01 \\
\hline 12 & 18 & 0.23 & 56 & 52 & 0.07 \\
\hline 13 & 12 & 0.18 & 82 & 70 & 0.15 \\
\hline 14 & 21 & 0.19 & 16 & 17 & 0.06 \\
\hline 15 & 20 & 0.21 & 31 & 30 & 0.03 \\
\hline 16 & 16 & 0.20 & 50 & 53 & 0.06 \\
\hline 17 & 14 & 0.20 & 76 & 67 & 0.12 \\
\hline 18 & 13 & 0.20 & 81 & 73 & 0.10 \\
\hline 19 & 9 & 0.21 & 94 & 91 & 0.03 \\
\hline 20 & 19 & 0.19 & 27 & 28 & 0.04 \\
\hline \multicolumn{5}{|c|}{ Mean error percentage } & 0.08 \\
\hline
\end{tabular}


sole calculation of FS, none of the above situations could have been predicted. The reliability index, the probability of failure, and the FS should however, be studied together in order to reach a common and rational basis for engineering application. Evidence related to this conclusion may be reviewed from data given in table 5 . Other evidence can be deduced from figure 11 which illustrates the FS and probability of failure variations with depth. Graphs in figure 11 have been plotted based on the data obtained from two different boreholes located at Roja Hotel and Shazdeh Bridge situated in the region.

\section{Proposed new relations}

\subsection{Liquefaction probability, N-SPT and CSR}

As mentioned earlier, liquefaction potential depends on various parameters such as: $\sigma_{v}, \sigma_{v}^{\prime}, a_{\max }$, $Z, M_{w}$, and $\left(N_{1}\right)_{60 c s}$. These parameters are divided into two major groups, namely, the soil strength parameters and the earthquake parameters. The two main parameters $\left(N_{1}\right)_{60 c s}$ and CSR should be selected so that they would represent these two groups and hence could define the soil's liquefaction potential.

In order to facilitate the use of the proposed method in earthquake engineering, a relationship between earthquake parameters and soil strength is established to define the liquefaction probability. In order to establish such a relationship the reliability analysis has been conducted for each layer in a given borehole. It is started with calculation of the reliability index $(\beta)$ and is followed by determination of parameters such as probability of liquefaction $\left(P_{L}\right), \mathrm{CRR}, \mathrm{CSR}$ and FS. Finally, the nonlinear and multiple regression analyses of these parameters lead to the desired correlated regressed equations.

A computer program has been developed based on the proposed method which incorporates all the 180 records, each comprising of several data/ variables, obtained in the city of Babolsar. Multiple regressions were carried out, as part of the computer program, on these data. The regression analysis resulted in the following relation:

$$
P_{L}=\frac{1}{1+\exp \left[-\left(13.5285+0.3562\left(N_{1}\right)_{60 c s}+4.6113 \ln (\mathrm{CSR})\right)\right]} .
$$

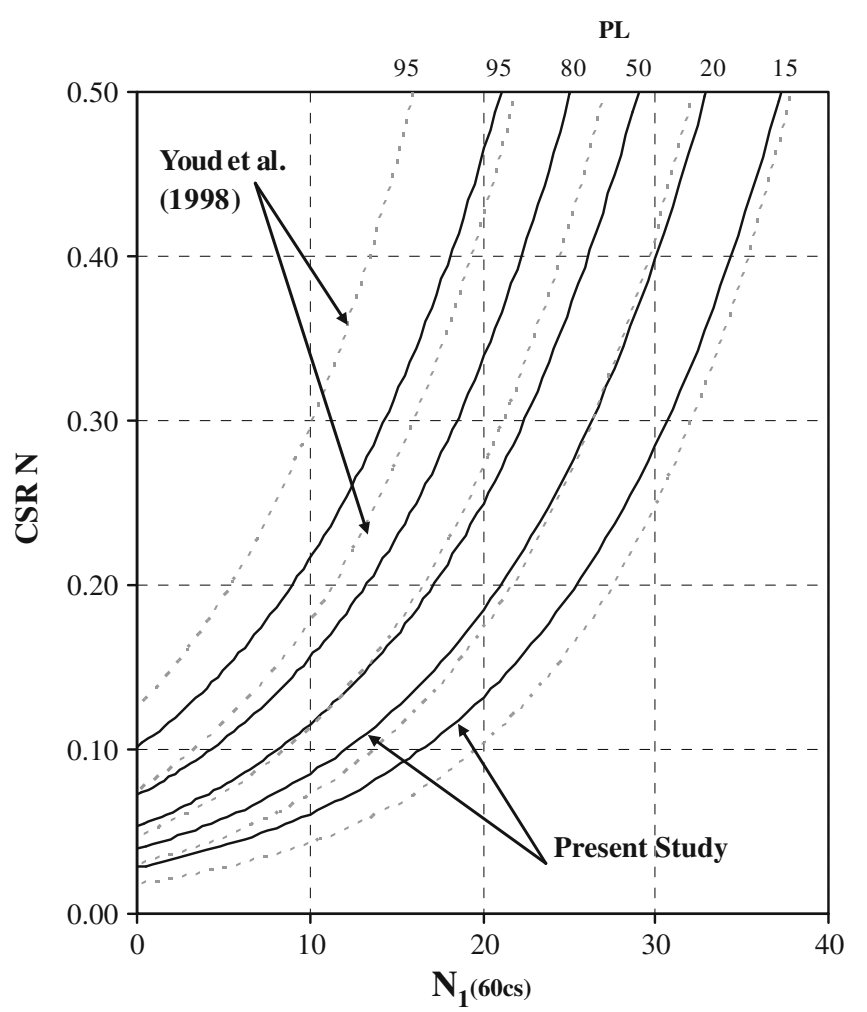

Figure 13. Comparison of the probabilistic bounds defined by Youd et al (1998) and those developed in the current study.

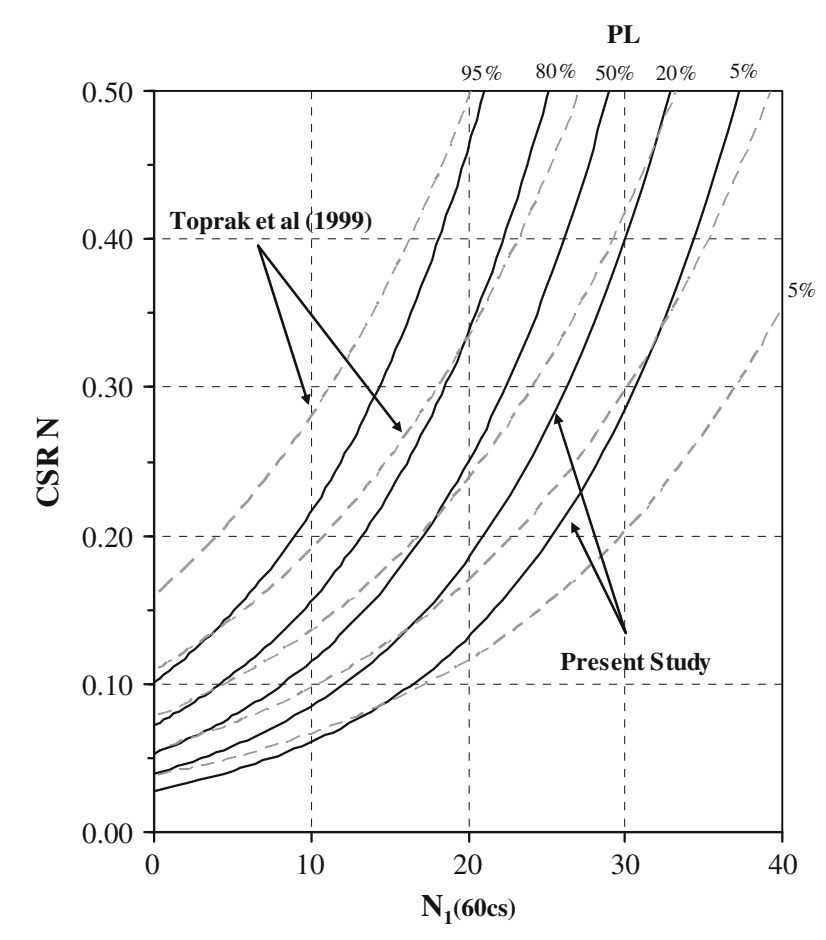

Figure 14. Comparison of the probabilistic bounds defined by Toprak et al (1999) and those developed in the current study. 


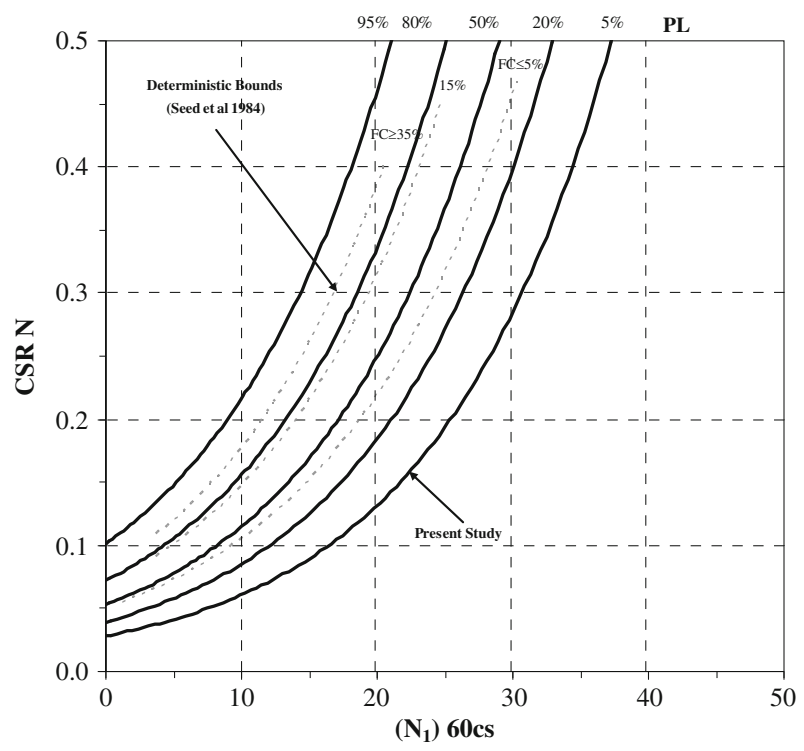

Figure 15. Comparison of the probabilistic bounds developed in this study and deterministic bounds suggested by Seed et al (1984).

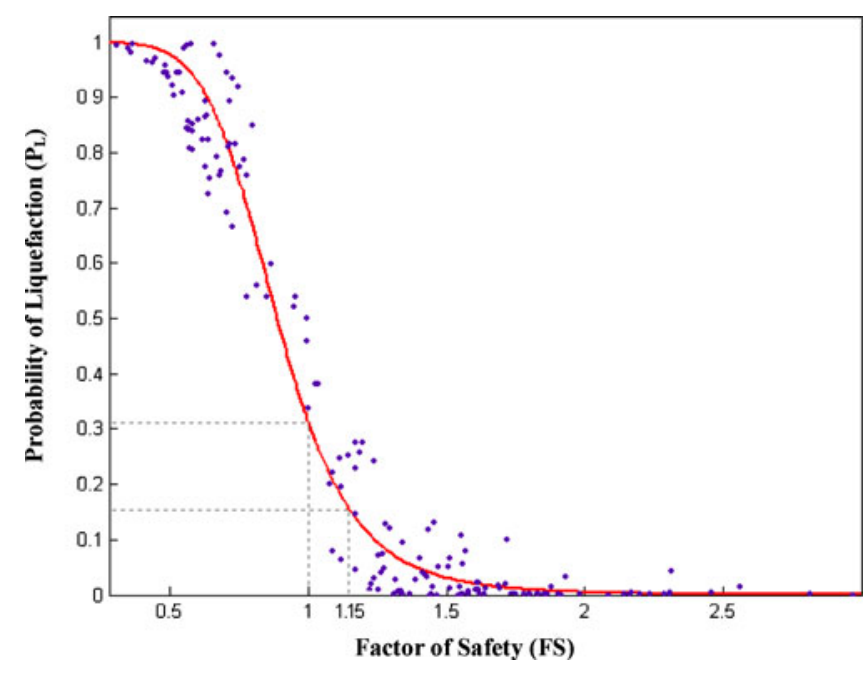

Figure 16. Probability of liquefaction variation with factor of safety.

The coefficient of correlation and the mean error were calculated as $95 \%$ and $10 \%$, respectively. The current study has been extended and investigated for further validation of the above relation. Hwang et al (2004) proposed a relation which is based on the data from liquefied and non-liquefied zones in Chi-Chi earthquake. This relation is used as a basis for comparison with the current proposed relation. The results of such comparison are summarized in table 7 .

Results presented in table 7 show a good correspondence between the two relations. It further demonstrates that the proposed relation has good accuracy and harmony with observed data.

Two boreholes, B4 and B7 and their corresponding data have been selected for further comparison.
The liquefaction probability variations with depth for two boreholes are presented in figure 12. The figure shows a comparison of probability of liquefaction based on the current approach and the method proposed by Hwang et al (2004), which is based on observational data. The figure depicts a good agreement between the two methods. Comparison of the probabilistic correlations for evaluation of liquefaction potential proposed by Youd et al (1998) (cited in Seed et al 2003) and those also developed probabilistically in the current study is shown in figure 13. Except for 95\% probability, generally good agreements are observed for given probabilities between the two methods. Figure 14 also shows a similar comparison made between the current study and that conducted by Toprak et al (1999). It is seen that, in spite of some spontaneous agreements through the graph, trends of curves are relatively different and predictions made by the two methods deviate. Figure 15 shows a comparison of the probabilistic correlations for evaluation of liquefaction potential developed in the current study and bounds developed deterministically by Seed et al (1984). Idriss and Boulanger (2006) state that "the application of probabilistic methods to the development of liquefaction correlations has often suffered from not including experimental and theoretical constraints on the liquefaction correlations at high CRR and $\left(N_{1}\right)_{60}$ values". Consequently, such probabilistic methods often predict probabilities of liquefaction at high $\left(N_{1}\right)_{60}$ values that are unreasonably high. It is believed that including experimental and theoretical findings in the development of probabilistic relations would improve results in the upper range of CRR and $\left(N_{1}\right)_{60}$ values. While the GA concept used in the current study rationally imposes constraints on the set of objective functions, through equations (30-33), to calculate the probability of liquefaction, this conclusion may appear not applicable for the current approach.

\subsection{Liquefaction potential and factor of safety}

The reliability analysis not only introduces a rational framework to consider the uncertainties in strength and loads, but also gives an insight into adopting a systematic method for selecting the FS in special circumstances; which may be regarded as a non-conventional FS.

An interesting and most important advantage of reliability approach developed here for investigation of the liquefaction potential is that the liquefaction probability can be qualitatively calculated using the FS. In figure 16, the probabilities of liquefaction and the corresponding FS calculated for each of the 180 records are shown. 
The regression analysis resulted in the following relation between $P_{L}$ and FS.

$$
P_{L}=\frac{1}{1+(\mathrm{FS} / 0.8876)^{6.573}} .
$$

Coefficient of correlation obtained was 0.9567 , which shows a relatively good agreement between data and the proposed relation. It can be seen from figure 16, or be concluded from equation (35), that when $P_{L}$ approaches zero, the maximum FS is 2.25. Such an FS may result in an uneconomic design when comes into engineering practice. However, when FS varies between 1 and 1.5, the impact of uncertainties in calculations becomes more profound and the probability of liquefaction significantly changes in response to small variation in FS. If $P_{L}<15 \%$, for example, the liquefaction is improbable and it is equivalent to an FS of 1.15.

\section{Conclusions}

A general, or rather historical, tendency exists in engineering to use deterministic approaches for the problems and to rely on the factors of safety calculated accurately from the results. However, these results come with worries about approximations, and uncertainties. The tendency to use complementary or alternative methods such as probabilistic approaches to evaluate the failure probability has increased in recent decades in geotechnical engineering. Probabilistic analyses help engineers to reach a better decision and a better understanding of the degree of conservatism involved in the simple deterministic models.

Information related to SPT carried out in 26 boreholes located at different sites around Babolsar city have been gathered as a dataset and has been incorporated into a proposed reliability model to obtain the liquefaction potential at different layers. The study conducted in this research proposed the use of GA as a highly sophisticated technique associated with AFSOM method to carry reliability-based analysis and optimization process. It developed a powerful tool for assessing liquefaction potential. In this regard, a rational framework to evaluate the liquefaction potential was proposed which can be used as an applicable method in geotechnical engineering practice. Based on the relation developed in this study, the liquefaction potential can be directly calculated based on the estimated $P_{L}$, CSR and $\left(N_{1}\right)_{60 c s}$ while containing the mean error at less than $10 \%$ of the observational data. A further advantage of the proposed relation is that it relates $P_{L}$ and FS and hence it provides the possibility of making decisions based on liquefaction risk when deterministic approaches are considered. This could benefit geotechnical engineers who use common methods based on FS to evaluate liquefaction.

It was demonstrated, based on the discussion given in preceding sections that the higher FS against liquefaction was not always associated with a safer state if a reliability analysis was also applied to the problem. However, the ultimate judgment should be based on the values obtained for probability percentage of liquefaction occurrence and on the reliability analysis.

The results obtained for probability of liquefaction were compared with those obtained by other investigators. In some cases, good agreement was observed while in other cases, the results deviated.

\section{Acknowledgements}

The authors wish to express their gratitude to the anonymous reviewers for their guidance and critical review. Their constructive comments and valuable suggestions have led to considerable improvement in the manuscript and enhanced the quality of the present work to a great extent.

\section{References}

Afzalirad M 2006 Investigation into liquefaction hazard for city of Babolsar based on the reliability method; M.EngSc thesis, Shahid Bahonar University of Kerman.

Andrus R D and Stokoe K H 2000 Liquefaction resistance of soils from shear wave velocity; J. Geotech. Geoenviron. Eng. 126(11) 1015-1025.

Christian J T and Swiger W F 1975 Statistics of liquefaction and SPT results; J. Geotech. Eng. ASCE 101(11) 1135-1150.

Chen C J and Juang C H 2000 Calibration of SPT and CPT based liquefaction evaluation methods; In: Innovations applications in geotechnical site characterization (eds) Mayne $\mathrm{P}$ and Hryciw R, Geotechnical Special Publication, No. 97, ASCE, New York, pp. 49-64.

Ditleveson O 1981 Uncertainty modeling (New York: McGraw-Hill).

Donovan N C 1972 Earthquake hazards for building national bureau of standard build; Science Series 46, Building practice for disaster mitigation, Boulder, Colorado.

Goldberg D E 1989 Genetic algorithms in search, optimization, and machine learning; Addison-Wesley Publishing Co., Boston, MA, USA.

Haeri S M and Zolfaghari M R 1993 Investigation on liquefaction occurrence due to Manjil 1990 Earthquake; Research Report by Centre for Study on Countermeasures to Natural Hazards and Disasters.

Halder A and Tang W H 1979 Probabilistic evaluation of liquefaction potential; J. Geotech. Eng. ASCE 104(2) $145-162$.

Hwang J H, Yang C W and Juang D S 2004 A practical reliability-based method for assessing soil liquefaction potential; J. Soil Dynamics Earthquake Eng. 24 761-770.

Idriss I M 1999 An update to the Seed-Idriss simplified procedure for evaluating liquefaction potential; Proceedings TRB Workshop on New Approaches to Liquefaction, Publication No. FHWA-RD-99-165, Federal Highway Administration California. 
Idriss M and Boulanger R W 2004 Semi-empirical procedures for evaluating liquefaction potential during earthquakes; Proceedings of Joint Conference of the 11th International Conference on Soil Dynamics and Earthquake Engineering (SDEE) and the 3rd International Conference on Earthquake Geotechnical Engineering (ICEGE), Berkeley, California, pp. 32-56.

Idriss I M and Boulanger R W 2006 Semi-empirical procedure for evaluating liquefaction potential during earthquakes; J. Soil Dynamics Earthquake Eng. 26 115-130.

Idriss I M and Boulanger R W 2008 EERI Monograph on Soil liquefaction during earthquakes, 261p.

Iwasaki T, Tatsuoka F, Tokida K and Yasuda S 1978 A practical method for assessing soil liquefaction potential based on case studies at various sites in Japan; Proceedings of 2nd International Conference on Microzonation for Safer Construction - Research and Application 2 885-896.

Juang C H, Rosowsky D V and Tang W H 1999 Reliability based method for assessing liquefaction potential of soils; J. Geotech. Geoenviron. Eng. 125(8) 684-689.

Juang C H, Jiang T and Andrus R D 2002 Assessing probability methods for liquefaction potential evaluation; J. Geotech. Geoenviron. Eng. 128(7) 580-589.

Juang C H, Fang S Y and Khor E H 2006 First order reliability method for probabilistic liquefaction triggering analysis using CPT; J. Geotech. Geoenviron. Eng. ASCE 132(3) 337-349.

Krishnakumar K and Goldberg D E 1992 Control system optimization using genetic algorithms; J. Guidance Control Dynamics 15(3) 735-740.

Liao S S C, Veneziano D and Whitman R V 1988 Regression models for evaluating liquefaction probability; J. Geotech. Eng. ASCE 114(4) 389-411.

Low B K and Tang W H 1997 Efficient reliability evaluation using spreadsheet; J. Eng. Mech. ASCE 123(7) 749-752.

McCully C and Bleobaum C L 1996 A genetic tool for optimal design sequencing in complex engineering system; Struct. Optim. J. 12 186-201.

Olsen R S 1997 Cyclic liquefaction based on the cone penetration test; Procedings NCEER Workshop on Evaluation of Liquefaction resistance of Soil, Tech. Rep., NCEER97-0022, State University of New York at Buffalo, pp. $225-276$.

Olsen R S and Koester J P 1995 Prediction of liquefaction resistance using the CPT; Proceedings of International Symposium on Cone Penetration Testing, Balkema, Rotterdam, 2 251-256.

Rauch A F 1997 Soil liquefaction in earthquakes; http:/ Scholarlib.vt.edu/theses/available/etd-219182249741411/ unrestricted/chp02.pdf.

Robertson P K and Wride C E 1998 Evaluating cyclic liquefaction potential using the cone penetration test; Can. Geotech. J. 35(3) 442-59.

Seed H B and Idriss I M 1971 Simplified procedure for evaluating soil liquefaction potential; J. Soil Mech. Found. ASCE 97(9) 1249-1273.

Seed H B and Idriss I M 1982 Ground motions and soil liquefaction during earthquakes; Berkeley, CA: Earthquake Engineering Research Institute; p. 134.

Seed H B, Tokimatsu K, Harder Jr, Leslie F and Chung R 1984 The influence of SPT procedures on soil liquefaction resistance evaluations; Report No. UCB/EERC-84/15, Earthquake Engineering Research Center, University of California, Berkeley.
Seed H B, Tokimatsu K, Harder L F and Chung R 1985 Influence of SPT procedures in soil liquefaction resistance evaluations; J. Geotech. Eng. ASCE 111(12) 1425-1445.

Seed R B, Cetin K O, Moss R E S, Kammerer A M, Wu J, Pestana J M and Riemer M F 2001 Recent advances in soil liquefaction engineering and seismic site response evaluation; Proceedings 4th International Conference and Symposium on Recent Advances in Geotechnical Earthquake Engineering and Soil Dynamics, University of Missouri, Rolla, Paper SPL-2.

Seed R B, Cetin K O, Moss R E S, Kammerer A M, Wu J, Pestana J M, Riemer M F, Sancio R B, Bray J D, Kayen R E and Faris A 2003 Recent advancements in soil liquefaction engineering: A unified and consistent framework; Keynote Presentation, 26th Annual ASCE Los Angeles Geotechnical Spring Seminar, H.M.S. Queen Mary, Long Beach, California, April 30.

Shahpasandzadeh M and Zare M 1995 Primary seismic survey, seismic profiling and seismic hazard zoning of Mazandarn Province; Report by Int. Institute of Seismology and Earthquake Engineering (IISEE) Iran (in Persian language).

Suzuki Y, Tokimatsu K, Koyamada K, Taya Y and Kubota Y 1995 Field correlation of soil liquefaction based on CPT data; Proceedings International Symposium on Cone Penetration Testing CPT 95, Balkema, Rotterdam, 2 $583-588$.

Toprak S, Holzer T L, Bennett M J and Tinsley J C 1999 CPT- and SPT-based probabilistic assessment of liquefaction; Proceedings of 7th US-Japan Workshop on Earthquake resistant design of lifeline facilities and countermeasure against liquefaction, Multidisciplinary Centre for Earthquake Engineering Research, Buffalo, N.Y., pp. 69-86.

Youd T L and Idriss I M 1997 Evaluation of liquefaction resistance of soils; Proceedings of NCEER Workshop on Evaluation of Liquefaction Resistance of Soils, Tech. Rep., NCEER-97-0022, State University of New York, Buffalo.

Youd T L and Noble S K 1997 Liquefaction criteria based statistical and probabilistic analysis; Proceedings of NCEER Workshop on Evaluation of Liquefaction Resistance of Soils., Tech. Rep., NCEER-97-0022, State University of New York, Buffalo, pp. 201-216.

Youd T L, Idriss I M, Andrus R D, Arango I, Castro G, Christian J T, Dobry R, Finn WDL, Harder Jr, leslie F, Hynes ME, Ishihara K, Koester JP, Liao SSC, Marcuson W F III, Martin G R, Mitchell J K, Moriwaki Y, Power M S, Robertson P K, Seed R B and Stokoe K H II 1997 Summary Paper; Proceedings of NCEER Workshop on Evaluation of Liquefaction Resistance of Soils; NCEER97-0022.

Youd T L, Idriss I M, Andrus R D, Arango I, Castro G, Christian J T, Dobry R, Finn W D L, Leslie F, Harder Jr, Hynes $\mathrm{M}$ E, Ishihara $\mathrm{K}$, Koester $\mathrm{J} \mathrm{P}$, Liao $\mathrm{S} \mathrm{S} \mathrm{C}$, Marcuson W F III, Martin G R, Mitchell J K, Moriwaki Y, Power M S, Robertson P K, Seed R B and Stokoe K H 2001 II. Liquefaction Resistance of Soils: Summary Report from the 1996 NCEER and Liquefaction Resistance of Soils; J. Geotech. Geoenviron. Eng. 127(10) 817-833, 1998 NCEER/NSF Workshops on Evaluation of Liquefaction Resistance of Soils. http:// www.bhrc.ac.ir/Portal/Default.aspx?alias=www.bhrc.ac. ir/portal/geotechnic IIEES; http://www.iiees.ac.ir/iiees/ English/Pulication/eng_Publication_jsee.html. 